\title{
Produção e qualidade de cultivares de melão em Savana de Boa Vista, Roraima $^{1}$
}

\author{
Ignácio Lund Gabriel da Silva Carmo ${ }^{2}$, Rosinaldo de Sousa Ferreira ${ }^{3}$, Jose Thyago Aires Souza ${ }^{3}$, \\ Lucimara Ferreira de Figueredo ${ }^{3}$, Roberto Dantas de Medeiros ${ }^{4}$
}

\author{
${ }^{1}$ Submetido em: 20-03-2016 e aprovado em: 04-07-2017 \\ ${ }^{2}$ Mestre em Produção Vegetal, POSAGRO, Universidade Federal de Roraima; e-mail: \\ ignacio.carmo@yahoo.com.br \\ ${ }^{3}$ Programa de Pós-Graduação em Agronomia (PPGA), Universidade Federal da Paraíba (UFPB), Areai-PB, CEP: \\ 58397-000; e-mail: rosinaldoagrarias@hotmail.com; thyago.agro@ hotmail.com; lucimara.ufpb@gmail.com \\ ${ }^{4}$ Pesquisador Embrapa Roraima, Boa Vista-RR, CEP: 69301-970; e-mail: roberto.medeiros@embrapa.br
}

\begin{abstract}
Resumo - A escolha de uma cultivar adaptada às condições edafoclimaticas de determinada região é a base para se alcançar boas produtividades e rendimento econômico. Objetivou-se com este trabalho avaliar a características produtivas e de qualidade de cultivares de melão em Savana de Boa Vista, Roraima. O experimento foi realizado em condições de campo na sede da Embrapa Roraima em Boa Vista, estado de Roraima, Brasil. Os tratamentos referem-se ao cultivo de cinco cultivares de melão: T1 - Valenciano Amarelo, T2 - Pele de Sapo Juazeiro, T3 Cantaloupe Harper, T4 - Ashira Amarelo e T5 - Gália Néctar, com seis repetições. As parcelas constituíram-se de uma fileira de plantas com $6 \mathrm{~m}$ de comprimento, espaçadas $3,5 \mathrm{~m}$ entre linhas e $0,5 \mathrm{~m}$ entre plantas. Para avaliação da adaptabilidade das diferentes cultivares de melão foram analisadas as seguintes variáveis: número de frutos ha${ }^{1}$, massa média total $\left(\mathrm{kg}_{\text {fruto }}{ }^{-1}\right)$, além da produtividade $\mathrm{kg} \mathrm{ha}^{-1}$. Posteriormente, foram selecionados cinco frutos comerciais por parcela para avaliação da qualidade quanto ao teor de sólidos solúveis por refratometria $\left({ }^{\circ} \mathrm{Brix}\right)$ e o pH. A cultivar Gália Néctar e Pele de Sapo Juazeiro apresentaram maior número de frutos e massa média de fruto, respectivamente. O meloeiro Cantalupe Harper obteve maior produtividade e qualidade dos frutos. As cultivares estudadas apresentaram diferenças em relação aos componentes de produção e qualidade sob as condições edafoclimáticas de Savana Boa Vista-RR.
\end{abstract}

Palavras chave: Adaptabilidade; Variedades; Cucumis melo L.; Produtividade

\section{Production and quality of melon cultivars in Savana de Boa Vista, Roraima}

\begin{abstract}
The choice of appropriate cultivate the edaphoclimatics conditions in determined region is the basis for achieving good productivities and economic returns. The objective of this study was to evaluate the productive characteristics and quality of melon cultivars in Savannah of Boa Vista, Roraima. The experiment was conducted under field conditions at the headquarters of Embrapa Roraima in Boa Vista, Roraima state, Brazil. The treatments refer to the cultivation of five melon cultivars: T1 - Valenciano Yellow, T2 - Piel of Frog Juazeiro, T3 - Cantaloupe Harper, T4 - Ashira Yellow and T5 - Gallia nectar, with six replications. To evaluate the adaptability of the different melon cultivars the following variables were analyzed: number of fruits $\mathrm{ha}^{-1}$, total average mass (kg fruit $\left.{ }^{1}\right)$, Besides productivity $\mathrm{kg} \mathrm{ha}^{-1}$. Posteriorly, five commercial fruits were selecteds per plot for quality evaluation as the content soluble solids by refractometry $\left({ }^{\circ}\right.$ Brix $)$ and $\mathrm{pH}$. The Cultivar Gaul Nectar and Piel of Frog Juazeiro presented more number of fruit and fruit average mass, respectively. The Cantaloupe melon Harper got higher productivity and fruit quality. The cultivars studied present differences in relation to production and quality components in edaphoclimatics conditions of Savannah Boa Vista-RR.
\end{abstract}

Keywords: Adaptability; Varieties; Cucumis melo L.; Productivity 


\section{Introdução}

O melão (Cucumis melo L.) é uma cucurbitácea cultivada em várias regiões do mundo e tem grande expressão econômica (DIAS et al., 2014). O cultivo da cultura no Brasil se iniciou na década de 60 , onde se estabeleceu em São Paulo e no Rio Grande do Sul, mas devido a sua adaptação as condições edafoclimáticas nas regiões tropicais, no início dos anos 80 propiciou a transferência da cultura para a região do Nordeste brasileiro, onde até os dias atuais predomina a produção da cultura, sendo esta região responsável por $94 \%$ da produção brasileira em 2014 (AGRIANUAL, 2015).

Quando uma variedade ou genótipo é cultivada em diferentes sistemas de produção pode não apresentar o mesmo desenvolvimento. $\mathrm{O}$ ambiente juntamente com o componente genético, são os grandes responsáveis pelas mudanças fisiológicas e morfológicas das plantas, tornando-se necessário testá-las nas condições locais, pois, seu comportamento varia em função das condições ambientais (DALASTRA; ECHER; HACHMANN, 2015).

De acordo com Carmo et al. (2015) a produtividade e as características de qualidade dos frutos de uma cultivar podem ser influenciadas diretamente pelas condições edafoclimáticas em que são submetidas. A escolha da cultivar é de fundamental importância para o sucesso da exploração, uma vez que devem ser considerados simultaneamente aspectos de mercado e comercialização, além de qualidades agronômicas quanto à suscetibilidade a doenças e pragas, resistência ao transporte, teor de sólidos solúveis, conservação pós-colheita, entre outras (SILVA et al., 2005; OLIVEIRA et al., 2015).

No estado de Roraima a produção de melão ainda é insuficiente para suprir as necessidades locais. Isso se deve à baixa tecnologia adotada pelos produtores devido à carência de resultados de pesquisa com tecnologia adequada para o cultivo desta curcubitacea. Neste sentido a identificação de cultivares mais adaptadas às condições edafoclimáticas, com altas produtividades e que atendam as exigências do mercado consumidor é de suma importância.

Objetivou-se com este trabalho avaliar a características produtivas e de qualidade de cultivares de melão em Savana de Boa Vista, Roraima.

\section{Material e Métodos}

$\mathrm{O}$ experimento foi realizado em condições de campo na sede da Embrapa Roraima, na cidade de Boa Vista, localizada nas coordenadas geográficas $022^{\circ} 45^{\prime} 26^{\prime \prime} \mathrm{N}, 60^{\circ} 43^{\prime} 53^{\prime \prime} \mathrm{W}$ e altitude 100 metros acima do nível do mar. Segundo a classificação de Köppen, o clima da região é do tipo Aw com duas estações climáticas bem definidas, uma chuvosa (abril-setembro) e outra seca (outubro-março) (ARAÚJO et al., 2001).

O solo da área experimental foi classificado conforme metodologia da EMBRAPA (2013), como Latossolo Amarelo de textura arenosa, cujas características físicas e químicas são apresentadas na (Tabela 1).

Tabela 1 Características físicas e químicas do solo da área experimental da Embrapa, Boa Vista-RR

\begin{tabular}{lcc}
\hline \multirow{2}{*}{ Atributo } & \multicolumn{2}{c}{ Camada de solo $(\mathrm{cm})$} \\
\cline { 2 - 3 } & $0-20 \mathrm{~cm}$ & $20-30 \mathrm{~cm}$ \\
\hline Areia (\%) & 851,9 & 843,8 \\
Silte (\%) & 47,5 & 46,6 \\
Argila (\%) & 100,6 & 109,7 \\
Matéria Orgânica (\%) & 16,92 & 10,35 \\
pH $\left(\mathrm{H}_{2} \mathrm{O}\right)$ & 6,4 & 6,6 \\
$\mathrm{P}\left(\mathrm{cmol}_{\mathrm{c}} \mathrm{dm}^{3}\right)$ & 92,22 & 164,88 \\
$\mathrm{~K}+\left(\mathrm{cmol}_{\mathrm{c}} \mathrm{dm}^{3}\right)$ & 0,22 & 0,17 \\
$\mathrm{Ca}{ }^{2}+\left(\mathrm{cmol}_{\mathrm{c}} \mathrm{dm}^{3}\right)$ & 1,44 & 1,77 \\
$\mathrm{Mg}^{2}+\left(\mathrm{cmol}_{\mathrm{c}} \mathrm{dm}^{3}\right)$ & 0,43 & 0,53 \\
$\mathrm{Al}^{3}+\left(\mathrm{cmol}_{\mathrm{c}} \mathrm{dm}^{3}\right)$ & 0,02 & 0,01 \\
\hline
\end{tabular}

Laboratório de análise de solo, Embrapa Roraima.

O experimento foi conduzido entre os meses de novembro de 2013 a fevereiro de 2014, em blocos casualizados com seis repetições. Os tratamentos constituíram de cinco cultivares de melão: T1 - Valenciano Amarelo, T2 - Pele de Sapo Juazeiro, T3 - Cantaloupe Harper, T4 Ashira Amarelo e T5 - Gália Néctar.

As parcelas foram constituídas por uma fileira de plantas com $6 \mathrm{~m}$ de comprimento, espaçadas 3,5 m entre linhas e $0,5 \mathrm{~m}$ entre plantas $\left(21 \mathrm{~m}^{2}\right)$ e área útil de $17,5 \mathrm{~m}^{2}(5,0 \mathrm{~m} \times 3,5 \mathrm{~m})$, constituída por uma linha de 10 plantas de melão. Foram semeadas duas sementes a cada $0,5 \mathrm{~m}$, aos doze dias após a emergência das plântulas, efetuou-se o desbaste, deixando duas plantas por metro, perfazendo um total de 5.714 plantas ha- ${ }^{-1}$.

O preparo do solo foi efetuado 21 dias antes da semeadura e constou de uma aração com grade aradora na profundidade de $20 \mathrm{~cm}$ e 
abertura de sulcos de plantio com $10 \mathrm{~cm}$ de profundidade. A adubação foi efetuada conforme os resultados da análise de solo a qual constou de $50 \mathrm{~kg} \mathrm{ha}^{-1}$ de $\mathrm{P}_{2} \mathrm{O}_{5}+100 \mathrm{~kg} \mathrm{ha}^{-1}$ de $\mathrm{K}_{2} \mathrm{O}+130$ $\mathrm{kg} \mathrm{ha}^{-1}$ de N. No plantio foi aplicado todo o fósforo $+30 \mathrm{~kg} \mathrm{ha}^{-1}$ de $\mathrm{N}+30 \mathrm{~kg} \mathrm{ha}^{-1} \mathrm{de}_{2} \mathrm{O}$, tendo como fonte: superfosfato simples, ureia e cloreto de potássio, respectivamente, aplicados via fertirrigação efetuada a cada dois dias, a partir de 12 dias após a emergência das plântulas.

A irrigação foi efetuada por gotejamento com vazão média de $3 \mathrm{~L} \mathrm{~h}^{-1}$, com monitoramento por meio de tensiometros, instalados nas profundidades de 15 a $30 \mathrm{~cm}$ localizados a $0,1 \mathrm{~m}$ das linhas de gotejadores. Adotou-se o manejo da água utilizado para a cultura da melancia conforme recomendado por (MEDEIROS et al., 2007).

Durante o experimento foram efetuadas duas capinas manuais aos 15 e 45 dias após a emergência das plântulas para evitar a proliferação de plantas daninhas, o manejo de pragas e doenças foi realizado conforme a necessidade, utilizando-se os produtos específicos por meio de pulverizações com inseticidas e fungicidas recomendados para a cultura. Todo o ciclo do melão foi em torno de 75 dias após a emergência das plântulas, realizaramse duas colheitas no mês de fevereiro de 2014 .

As variáveis analisadas dos componentes de produção foram: Número de frutos por hectare, obtido pela contagem dos frutos totais para comercialização da área útil da parcela e transformada em frutos por hectare (frutos $/ \mathrm{ha}^{-1}$ ). Massa média total de frutos para a comercialização, dividido pelo número total de frutos e expressa em quilograma fruto $^{-1}\left(\mathrm{~kg} /\right.$ fruto $^{-}$ $\left.{ }^{1}\right)$. Produtividade, avaliada na área útil, onde obteve-se a produção por parcela e transformouse para quilograma por hectare $(\mathrm{kg} / \mathrm{ha})$.

A avaliação da qualidade dos frutos foi realizada no laboratório pertencente à Embrapa Roraima, sendo selecionados cinco frutos comerciais por parcela, em seguida os frutos foram cortados longitudinalmente para retirada da polpa e homogeneização com ajuda de um processador. O suco foi liberado para a leitura diretamente no prisma do refratômetro digital de bancada modelo RTD-45. Foram avaliadas as seguintes características de qualidade: Sólidos Solúveis, determinado por refratometria, seguindo metodologia proposta por (IAL, 2008), cujos resultados foram expressos em ${ }^{\circ} \mathrm{Brix}$. $\mathrm{O} \mathrm{pH}$ (potencial hidrogêniônico) foi analisado em amostras constituídas de $10 \mathrm{~g}$ de polpa diluída em $100 \mathrm{ml}$ de água destilada, utilizando-se o pHgâmetro da marca Hanna Instruments modelo pH 300, sendo os resultados expressos em unidades de $\mathrm{pH}$, de acordo com IAL (2008).

Os dados foram submetidos à análise de variância com aplicação do teste $\mathrm{F}$ e as medias comparadas pelo teste de Tukey no nível de 5\% de probabilidade, utilizando-se o "software" SISVAR (FERREIRA, 2003).

\section{Resultados e Discussão}

Avaliando os resultados expostos quanto ao número de frutos por hectare (Tabela 2), as cultivares Cantaloupe Harper (T3) e Gália Néctar (T5) obtiveram os maiores valores, apresentando (18.571 e 20.142 frutos ha $^{-1}$, respectivamente), valores aproximados dos obtidos por Medeiros et al. (2007), que encontraram para a cultivar Cantaloupe Harper média de 17.044 frutos ha-1 . A cultivar Valenciano Amarelo (T1) obteve a menor quantidade de 7.143 frutos não diferenciando-se estatisticamente da Pele de Sapo (T2) com 7.286 frutos $\mathrm{ha}^{-1}$. Trabalhando com densidades de plantio de melão Pele de Sapo, Nunes et al. (2008) encontrou 17.900 frutos $\mathrm{ha}^{-1} \mathrm{em}$ uma densidade de 10.000 plantas $\mathrm{ha}^{-1}$. No presente trabalho a densidade de plantas foi de 5.714 frutos ha ${ }^{-1}$, o que demonstra coerência entre os dados obtidos para esta cultivar.

A massa média de fruto é uma das principais características para fins de seleção em plantas de melão, indicando a cultivar mais adaptada em uma determinada região. Para esta variável as cultivares Valenciano Amarelo e Pele de Sapo obtiveram as maiores médias (1,85 e 2,17 $\mathrm{kg}$ fruto $^{-1}$ ). Estes resultados são semelhantes aos obtidos por Dias (2014), que analisando a massa de fruto do melão "Pele de Sapo" sob lâmina de irrigação de $100 \%$, ou seja, em condições normais de fornecimento de água, os frutos apresentaram massa média de $2,2 \mathrm{~kg}$ fruto ${ }^{-1}$. 
Tabela 2 Média do número de frutos por hectare (NFH), massa média de frutos (MMF) e produtividade (PROD) de cinco cultivares de melão cultivados na Embrapa Roraima, Boa Vista - RR 2014.

\begin{tabular}{lccc}
\hline \multicolumn{1}{c}{ Cultivar } & NFH (unidade) & MMF (kg) & PROD (t ha-1) \\
\hline Valenciano Amarelo & $7.143 \mathrm{c}$ & $1,85 \mathrm{a}$ & $13,00 \mathrm{~b}$ \\
Pele de Sapo Juazeiro & $7.286 \mathrm{c}$ & $2,17 \mathrm{a}$ & $15,79 \mathrm{ab}$ \\
Cantaloupe Harper & $18.571 \mathrm{ab}$ & $1,28 \mathrm{~b}$ & $23,88 \mathrm{a}$ \\
Ashira Amarelo & $11.714 \mathrm{bc}$ & $1,25 \mathrm{~b}$ & $14,84 \mathrm{~b}$ \\
Gália Néctar & $20.142 \mathrm{a}$ & $0,57 \mathrm{c}$ & $11,77 \mathrm{~b}$ \\
Média & 12.971 & 1,42 & 15,85 \\
CV $(\%)$ & 15,03 & 19,23 & 17,12 \\
\hline
\end{tabular}

Médias seguidas da mesma letra, na coluna, não diferem entre si pelo teste de Tukey, a 5\% de probabilidade.

As cultivares de melão Cantaloupe Harper e Ashira Amarelo obtiveram massa média de 1,28 e $1,25 \mathrm{~kg}$ fruto $^{-1}$, respectivamente, sendo estatisticamente iguais, mas superiores à média de $0,57 \mathrm{~kg}$ fruto $^{-1}$ obtida com a Gália Néctar. Os dados obtidos estão coerentes quando comparados aos obtidos por Dantas (2010) e Silva Júnior et al. (2010) que analisando a massa média de frutos de melão Cantaloupe Harper obtiveram frutos em torno de $1,3 \mathrm{~kg}_{\text {fruto }}{ }^{-1}$.

A massa média está relacionada com o tamanho do fruto. A massa média das cultivares Valenciano Amarelo e Pele de Sapo atende as exigências do mercado europeu, principalmente da Espanha que prefere frutos com massa em torno de $2 \mathrm{~kg}$ fruto $^{-1}$ (PALÁCIO, 2011). No entanto a os melões Cantaloupe Harper e Ashira Amarelo se adequam as exigências do mercado internacional que prefere frutos com massa média por volta de $1 \mathrm{~kg}^{\text {fruto }^{-1}}$ (MORETTI; ARAÚJO, 2003).

A cultivar Cantaloupe Harper produziu em média $23,88 \mathrm{t} \mathrm{ha}^{-1}$ de frutos, esta produtividade embora superior, foi estatisticamente semelhante à média de $15,79 \mathrm{t} \mathrm{ha}^{-1}$ do meloeiro Pele de Sapo e superior às médias dos meloeiros Valenciano Amarelo, Ashira Amarelo e Gália Néctar (13,00, 14,84 e 11,77 $\mathrm{t} \mathrm{ha}^{-1}$, respectivamente).

A produtividade média obtida pelo meloeiro Cantaloupe Harper está acima da estimada por Queiroga et al. (2013) para esta cultivar que é de $23.000 \mathrm{~kg} \mathrm{ha}^{-1}$ e também da estabelecida por EMBRAPA (2010) como referência para as variedades do grupo dos cantaloupes, que é de $20.000 \mathrm{~kg} \mathrm{ha}^{-1}$. No entanto a produtividade média da cultivar Valenciano Amarelo está abaixo da obtida por Queiroga (2015) com o melão amarelo Goldex que foi de 25.225 Kg ha-1 e também da média nacional para meloeiros do grupo amarelo que é de $25.248 \mathrm{~kg}$ ha $^{-1}$ (IBGE, 2014).

A média da produtividade para cultivar Pele de Sapo foi inferior às obtidas por Nunes (2008) que teve como resultado a produtividade de $35 \mathrm{t} \mathrm{ha}^{-1}$. Em outro experimento Nunes et. al. (2006) obtiveram produtividade de 27 e $53 \mathrm{t} \mathrm{ha}^{-1}$. A produtividade no presente experimento comparando com a região do nordeste brasileiro não foi satisfatória para algumas cultivares, sendo que a região nordeste tem um intervalo de variação de 17 e $30 \mathrm{t} \mathrm{ha}^{-1}$, apenas a cultivar Cantaloupe Harper obteve essas médias comparadas.

Nas condições de cultivo de Boa Vista RR, em relação aos valores de sólidos solúveis, houve diferenças entre as cultivares Cantaloupe Harper e Ashira Amarelo que produziram frutos com 13,27 e 12,62 ${ }^{\circ}$ Brix, respectivamente (Tabela 3). As cultivares se diferem e ainda foram superiores às demais médias obtidas das cultivares Pele de Sapo Juazeiro, Gália Néctar e Valenciano Amarelo com mensuração em 9,25, 10,00 e $10,32{ }^{\circ}$ Brix, respectivamente, que não diferiram entre eles.

No entanto todas as cultivares mantiveram seu ${ }^{\circ}$ Brix acima da faixa mínima para exportação de melão para o continente europeu, que é entre 9,0 e $10,0^{\circ}$ Brix. Esta faixa de sólidos solúveis também é usada como parâmetro de qualidade na classificação de melões Cantaloupe pelo Departamento de Agricultura dos Estados Unidos (USDA). Gorgatti Neto et al., (1994) e Abreu et al. (2011) ressaltam que frutos com o Brix inferior a nove não são comercializáveis; de 9 a $12{ }^{\circ}$ Brix são comercializáveis e acima de $12{ }^{\circ}$ Brix são considerados melões extras. 
Tabela 3 Sólidos solúveis $\left({ }^{\circ}\right.$ Brix) e $\mathrm{pH}$ de cinco cultivares de melão cultivados na Embrapa Roraima, Boa Vista - RR 2013

\begin{tabular}{lcc}
\hline \multicolumn{1}{c}{ Cultivares } & SS $\left({ }^{\circ}\right.$ Brix $)$ & $\mathrm{pH}$ \\
\hline Valenciano Amarelo & $10,32 \mathrm{~b}$ & $5,17 \mathrm{a}$ \\
Pele de Sapo Juazeiro & $9,25 \mathrm{~b}$ & $5,56 \mathrm{a}$ \\
Cantaloupe Harper & $13,27 \mathrm{a}$ & $5,09 \mathrm{a}$ \\
Ashira Amarelo & $12,62 \mathrm{a}$ & $5,34 \mathrm{a}$ \\
Gália Néctar & $10,00 \mathrm{~b}$ & $5,36 \mathrm{a}$ \\
Média & 11,09 & 5,30 \\
CV $(\%)$ & 10,37 & 12,03 \\
\hline
\end{tabular}

Médias seguidas da mesma letra, na coluna, não diferem entre si pelo teste de Tukey, a 5\% de probabilidade.

Os resultados dos sólidos solúveis apresentados neste trabalho discordam com os obtidos por Miguel et. al. (2008), analisando o comportamento produtivo de nove tipos de melões amarelos, que apresentaram média de $8,20{ }^{\circ}$ Brix.

As cultivares Cantaloupe Harper e Ashira Amarelo superaram as demais cultivares, obtendo resultado semelhante a Nunes (2008) de 11,71 ${ }^{\circ}$ Brix estando acima dos resultados mínimos para às exigências do mercado internacional de 12 ${ }^{\circ}$ Brix.

Os valores médios de $\mathrm{pH}$ não se apresentaram significativamente diferentes entre os melões analisados, onde variaram entre 5,09 e 5,56 . Esses valores são inferiores aos obtidos por Santos (2014), avaliando o efeito de doses de biofertilizantes em melão harper, que encontrou valor de 5,9. O pH médio dos frutos foi de 5,30, sendo a cultivar Pele de Sapo Juazeiro e Gália Néctar superiores com $\mathrm{pH}$ de 5,56 e 5,36, respectivamente. Paduan; Campos; Clemente (2007), trabalhando com cultivares de melão em ambiente protegido encontrou resultados superiores para Pele de Sapo e Gália com 6,48 e 6,30 , respectivamente.

A avaliação do $\mathrm{pH}$ da polpa é de suma importância, segundo a classificação de Azeredo et.al. (2004) os resultados obtidos neste experimento evidenciam a boa qualidade dos frutos colhidos em Boa Vista - RR, pois a baixa acidez resulta em alimentos poucos susceptíveis ao desenvolvimento de microrganismos. Esta é determinante para a vida útil pós-colheita de frutos de melão, como deterioração do alimento com o crescimento de microrganismos, atividade das enzimas, retenção de sabor e odor de produtos e escolha de embalagem (CECCHI, 2003).

\section{Conclusão}

As cultivares de melão avaliadas expressam características diferentes quanto aos componentes de produção, sendo a cultivar Gália Néctar mais produtiva em número de frutos, enquanto os meloeiros Valenciano Amarelo e Pele de Sapo apresentam maior massa média de fruto;

Sob as condições edafoclimáticas de Savana de Boa Vista-RR, a cultivar Cantalupe Harper proporciona ao produtor maior produtividade e elevado teor de sólidos solúveis, além de $\mathrm{pH}$ da polpa inferior às demais cultivares, estas características atendem a exigência do mercado consumidor.

\section{Referências}

ABREU, F. L. G.; CAZETTA, J. O.; XAVIER, T. F., Adubação fosfatada no meloeiroamarelo: reflexos na produção e qualidade dos frutos, Revista Brasileira de Fruticultura, v. 33, n. 4, p. 1266-1274, 2011.

AGRIANUAL. Anuário da Agricultura Brasileira. São Paulo: FNP Consultoria e Agro Informativos, 2015, 496p.

ARAUJO, W. F. et al. Precipitação pluviométrica mensal provável em Boa Vista, Estado de Roraima, Brasil. Revista Brasileira de Engenharia Agrícola e Ambiental, v. 5, n. 3, p. 563-567, 2001.

AZEREDO, H. M. C.; BRITO, E. S. Tendências em Conservação de Alimentos. In: AZEREDO, H. M. C. (Ed.) Fundamentos de Estabilidade de Alimentos. Fortaleza: Embrapa Agroindústria Tropical, cap. 6, p. 135-150, 2004.

CARMO, I. L. G. S. et al. Desempenho agronômico de cultivares de melancia no cerrado de Boa Vista, Roraima. Revista Agro@mbiente On-line, v. 9, n. 3, p. 268274, julho-setembro, 2015.

CECCHI, H. M. Fundamentos teóricos e práticos em análises de alimentos. 2. ed. Campinas: Editora da Unicamp, 2003, 302 p.

DALASTRA, G. M.; ECHER, M. M.; HACHMANN, T. L. Desempenho de cultivares de melão, em função do número de frutos por planta. Journal of Agronomic Sciences, v. 4, n. 1, p. 26-41, 2015. 
DANTAS, D. C. Função de produção do meloeiro em resposta à fertirrigação nitrogenada e potássica na microrregião de Mossoró. 2010. 76 f. Dissertação (Mestrado em Agronomia) - Universidade Federal do Semiárido, Mossoró, 2010.

DIAS, V. G. Crescimento, fisiologia e produção do meloeiro "Pele de sapo" cultivado sob diferentes lâminas de irrigação. 2014. 84 f. Dissertação (Mestrado em Ciências Agrárias) Universidade Estadual da Paraíba - UEPB Campina Grande, 2014.

EMBRAPA. Sistema de produção do melão. Petrolina: Embrapa Semiárido. MBRAPA, $2010 . \quad$ Disponível em: http://sistemasdeproducao.cnptia.embrapa.br/ FontesHTML/Melao/SistemaProducaoMelao/ cultivares.html> Acesso em: 08 mar. 2016.

EMBRAPA. Sistema Brasileiro de Classificação de Solos. $2^{\mathrm{a}}$ ed. Rio de Janeiro: Embrapa Solos, 2013. 306p.

FERREIRA, D. F. Programa SISVARprograma de análises estatísticas. Lavras: UFLA, 2003.

GORGATTI NETO, A. et al. Melão para exportação: procedimento de colheita e póscolheita. Brasília, Embrapa, 1994. 37p.

INSTITUTO ADOLFO LUTZ - IAL. Métodos físico-químicos para análise de alimentos. $1^{\mathrm{a}}$ ed. São Paulo: Instituto Adolfo Lutz, 2008, $1020 \mathrm{p}$.

MEDEIROS, J. F. et al. Produção de melão Cantaloupe influenciado por coberturas do solo, agrotêxtil e lâminas de irrigação. Horticultura Brasileira, v. 25, n. 4, p. 538543, 2007.

MIGUEL, A. A. et al. Comportamento produtivo e características pós-colheita de híbridos comerciais de melão amarelo, cultivados nas condições do Ceará. Ciência Agrotecnica, v. 32, n. 3. p. 756-761, 2008.

MORETTI, C. L.; ARAÚJO, J. L. P. Tecnologia de pós-colheita e comercialização. In: SILVA, H. R.; COSTA, N.D. (Eds.) Melão, Produção Aspectos técnicos, Petrolina. Embrapa Semiárido, 2003, p.121-129.

NUNES G. H. S. et al. Estabilidade fenotípica de híbridos de melão amarelo avaliados no Polo
Agroindustrial Mossoró-Assu. Pesquisa Agropecuária Brasileira, v. 41, n. 2, p. 5767, 2006.

NUNES, G. H. S. et al. Produtividade e qualidade de frutos de melão pele-de-sapo em duas densidades de plantio. Horticultura Brasileira, v. 26, n. 1, p. 236-239, 2008.

OLIVEIRA, J. B. et al. Rendimento e qualidade de frutos de melancia em diferentes épocas de plantio. Revista Caatinga, v. 28, n. 2, p. $19-$ 25, 2015.

PADUAN, M. T.; CAMPOS, R. P.; CLEMENTE, E. Qualidade dos frutos de tipos de melão, produzidos em ambiente protegido. Revista Brasileira de Fruticultura, v. 29 n. 3, p. 538, 2007.

PALÁCIO, V. S. Concentração da solução nutritiva do meloeiro cultivado em substrato de fibra de coco sob ambiente protegido. 2011. $72 \mathrm{f}$. Dissertação (Mestrado em Irrigação e Drenagem) Universidade Federal Rural do Semiárido, Mossoró, 2011.

QUEIROGA, F. M. et al. Produção e qualidade de frutos de melão Harper em função de doses de boro. Agropecuária Científica do Semiárido, v. 9, n. 3, p. 87-93, 2013.

QUEIROGA, F. M. Doses e fontes de nitrogênio, fósforo e potássio para produção dos melões amarelo e harper em solo com histórico de cultivo de meloeiro. 2015. 183f. Tese (Doutorado em Fitotecnia) Universidade Federal Rural do Semiárido, Mossoró, 2015.

SANTOS, A. P. G. et al. Produtividade e qualidade de frutos do meloeiro em função de tipos e doses de biofertilizantes. Horticultura Brasileira, v. 32, n. 2, p. 409-416, 2014.

SILVA, L. A.; I. R. et al. Estudo de aspectos quantitativos e qualitativos de frutos de genótipos de melão. Revista Ciência Agronômica, v. 36, n. 3, p. 310-315, 2005.

SILVA JUNIOR, M. et al. Resposta do meloeiro à fertirrigação controlada através de íons da solução do solo: parâmetros produtivos. Revista Brasileira de Engenharia Agrícola e Ambiental, v. 14, n. 7, p. 723-729. 2010. 